\title{
Continuous ventilation using a modified laparoscopic port and laryngeal mask airway during flexible bronchoscopic intubation
}

\author{
Zhuan Zhang, MD $\cdot$ Jiapeng Huang, MD, PhD $\cdot$ Wenxi Tang, MD
}

Received: 16 March 2017/Revised: 29 March 2017/ Accepted: 12 April 2017 / Published online: 24 April 2017

(c) Canadian Anesthesiologists' Society 2017

\section{To the Editor,}

A laryngeal mask supraglottic airway can be used to assist ventilation in the setting of an unanticipated difficult airway. Inserting an endotracheal tube (ETT) using a flexible bronchoscope (FB) through the laryngeal mask can be challenging and sometimes time consuming.

To ensure continuous ventilation and oxygenation during this process, we constructed a special ventilator adaptor using materials that are readily available in the operating room (Figure A). This adaptor allows FB manipulation and endotracheal intubation through the laryngeal mask.

To construct the adaptor, the operating tube of a $12-\mathrm{mm}$ laparoscopic trocar (Versaport ${ }^{\mathrm{TM}}$ PlusV2 bladed trocar; Covidien PLC, Mansfield, MA, USA) was cut to a length

\section{Z. Zhang, MD}

Department of Anesthesiology, The Affiliated Hospital of Yangzhou University, Yangzhou University, Yangzhou, People's Republic of China

\section{Z. Zhang, MD}

Department of Anesthesiology, The First Peoples' Hospital of Yangzhou, Yangzhou, People's Republic of China

J. Huang, MD, $\mathrm{PhD}$

Department of Anesthesiology, Perioperative Medicine, University of Louisville, Louisville, KY, USA

J. Huang, MD, PhD

Department of Anesthesiology, Jewish Hospital, University of Louisville, Louisville, KY, USA

\section{W. Tang, MD ( $\square)$}

Department of Anesthesiology, Qilu Hospital of Shandong

University (Qingdao), No. 758 Hefei Road, Qingdao,

People's Republic of China

e-mail: wenxitangqd@163.com of $1.5 \mathrm{~cm}$. The flip-top seal of the trocar is large enough to permit an FB and/or an ETT (internal diameter $\leq 8.0 \mathrm{~mm}$ ) to pass through it. The elbow of a conventional anesthesia ventilator circuit was cut to $2 \mathrm{~cm}$, allowing it to fit into the operating tube end of the trocar (Figure A). The larger end of the anesthesia circuit elbow was used to join the LMA ${ }^{\circledR}$ Classic $^{\text {TM }}$ (Teleflex; Westmeath, Ireland) directly. The stopcock of the trocar was removed, and the body of a 2-mL syringe (a size similar to that of the stopcock to ensure a tight fit) was inserted. It was then connected to a standard ETT connector for the ventilator circuit (Figure B).

After routine anesthesia induction, an LMA (size 3 or 4) is inserted and confirmed to ensure proper placement. The adaptor can then be connected to the LMA, and mechanical ventilation is continued throughout the intubation process (Figure B). The FB with a preloaded ETT is inserted through the unique adaptor and the LMA (Figure B). When the vocal cords are identified, the FB is advanced into the trachea. The preloaded ETT can then be slid into the trachea over the FB (Figure B). After correct ETT placement is confirmed, the cuff of the ETT is inflated. The LMA is then deflated and left in the mouth (or it can be removed).

The LMA is an important option in the American Society of Anesthesiologists' difficult airway algorithm. ${ }^{1}$ The ETT however, is still the most definitive and secure airway. As blind insertion of an ETT through an LMA has varied success, guidance using an FB is a much better choice. For novice practitioners, maintaining ventilation during FB manipulation could allow more time and better control of the situation.

Two methods have been previously reported to maintain ventilation during FB-aided tracheal intubation through LMAs. Each has used a swivel elbow with a self-sealing suction port to allow insertion of the $\mathrm{FB} .{ }^{2,3}$ Our adaptor has 


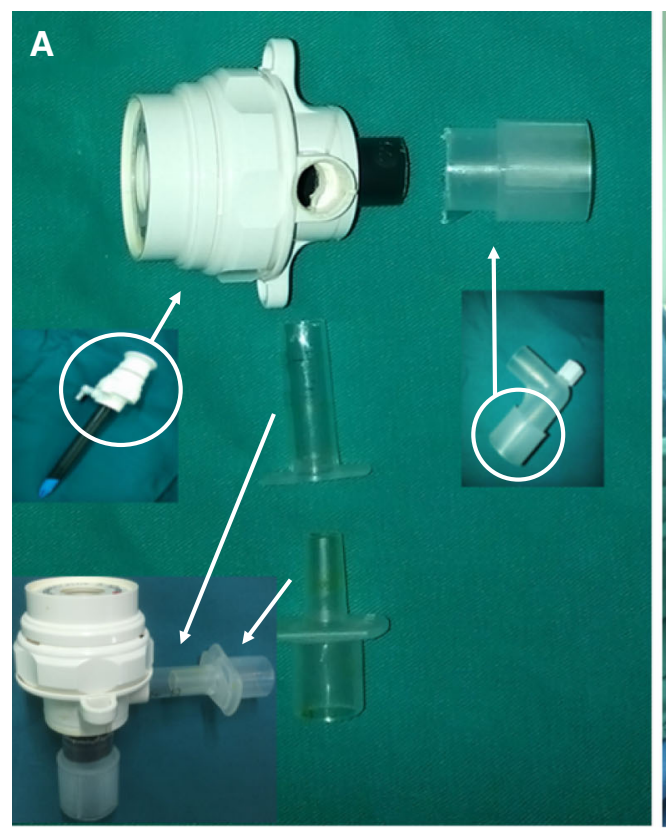

Figure In image A, a laparoscopic port has been cut, leaving $1.5 \mathrm{~cm}$ of the trocar in place to which a cut elbow connector can be attached. This, in turn, allows a modified port to be attached to a laryngeal mask airway (LMA) (image B). The stopcock of the trocar has been removed, and the body of a $2 \mathrm{~mL}$ syringe is inserted, through which a standard endotracheal tube (ETT) connector can be placed. The

several advantages. First, the self-sealing suction port of a commercially available elbow adaptor swivel is relatively small (about $3 \mathrm{~mm}$ ) and accommodates only an FB or pediatric-size ETT. Our adaptor's self-sealing diaphragm allows greater expansion and thus accommodates both larger FBs and adult ETTs to pass through. Second, our adaptor's double sealing diaphragm automatically seals and closes during insertion of an FB and ETT. In contrast, the elbow adaptor swivel requires manual closing and opening of the lid for FB/ETT insertion. Third, the space between the FB and the LMA of our adaptor is much larger and ensures more effective ventilation.

Thus, using our modified laparoscopic port with a LMA safely allows uninterrupted ventilation during FB intubation in the unanticipated difficult airway.

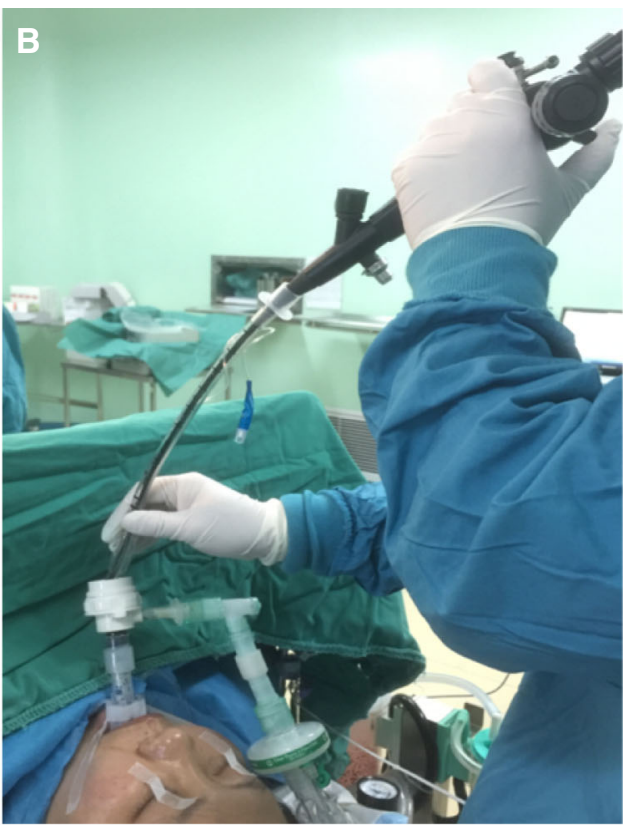

ventilator breathing circuit can be attached to the ETT connector. It allows mechanical ventilation to be continued during flexible bronchoscopic (FB) intubation (image $\mathrm{B}$ ). The FB, preloaded with an ETT, is inserted through the adaptor and the LMA. When the vocal cords are identified, the FB is advanced into the trachea and the preloaded ETT then slid into the trachea over the FB

\section{Conflicts of interest None declared.}

Editorial responsibility This submission was handled by Dr. Hilary P. Grocott, Editor-in-Chief, Canadian Journal of Anesthesia.

\section{References}

1. Benumof JL. Laryngeal mask airway and the ASA difficult airway algorithm. Anesthesiology 1996; 84: 686-99.

2. Chen L, Sher SA, Aukburg SJ. Continuous ventilation during translaryngeal mask airway fiberoptic bronchoscope-aided tracheal intubation. Anesth Analg 1996; 82: 891-2.

3. Yang SY, Son SC. Laryngeal mask airway-guided fibreoptic tracheal intubation in a child with a lingual thyroglossal duct cyst. Paediatr Anaesth 2003; 13: 829-31. 